\title{
Nanoformulated Antiretrovirals for Penetration of the Central Nervous System: State of the Art
}

Luisa Fiandra, 1

Amedeo Capetti, 2

Luca Sorrentino, 1

Fabio Corsi, $1,3 * \frac{3}{, 3}$

Email fabio.corsi@unimi.it

1 Department of Biomedical and Clinical Sciences "Luigi Sacco", University of Milan, via G. B. Grassi 74, 20157 Milan, Italy

2 Division of Infectious Diseases, ASST Fatebenefratelli Sacco - "Luigi Sacco" University Hospital, via G. B. Grassi 74, 20157 Milan, Italy

3 Surgery Department, Breast Unit, ICS Maugeri S.p.A. SB, via S. Maugeri 10, Pavia, 27100 Italy

\section{Abstract}

The central nervous system is a very challenging HIV-1 sanctuary. But, despite complete suppression of plasmatic viral replication with current antiretroviral therapy, signs of HIV-1 replication can still be found in the cerebrospinal fluid in some patients. The main limitation to achieving HIV-1 eradication from the brain is related to the suboptimal concentrations of antiretrovirals within this site, due to their low permeation across the blood-brain barrier. In recent years, a number of reliable nanotechnological strategies have been developed with the aim of enhancing antiretroviral drug penetration across the blood-brain barrier. The aim of this review is to provide an overview of the different nanoformulated antiretrovirals, used in both clinical and preclinical studies, that are designed to improve their delivery into the brain by active or passive permeation mechanisms through the barrier. Different nanotechnological approaches have proven successful for optimizing antiretrovirals delivery to the central nervous system, with a 
likely benefit for HIV-associated neurocognitive disorders and a more debated contribution to the complete eradication of the HIV-1 infection.

\section{Keywords}

Central nervous system

HIV

NeuroAIDS

Antiretrovirals

Nanotechnology

Blood-brain barrier

\section{Introduction}

Great progress has been made in antiretroviral therapy in the last decades, with a significant improvement in clinical outcomes for HIV-1-infected patients (Sarmati et al. 2012). However, complete eradication of HIV-1 remains an unmet need. The main concern is the persistent viral replication in some physiological reservoirs, including anatomical (i.e. male genital tract, lymph nodes, gut, bone marrow lymphoid structures and the central nervous system) or cellular (i.e. latently infected CD4+ T cells, macrophages) compartments. These sites, where HIV-1 is able to replicate despite treatment, are poorly permeable to most antiretroviral drugs (ARVs), precluding a real possibility of cure for patients (Svicher et al. 2014). Particularly, the central nervous system (CNS) is a critical anatomical sanctuary for HIV-1. Indeed, HIV-1 can quickly penetrate into the CNS after initial systemic infection (Kramer-Hämmerle et al. 2005), promoting independent replication even if the plasmatic viral load is suppressed (Canestri et al. 2010). HIV-1 invades the CNS very early after infection: it has been retrieved in the cerebrospinal fluid (CSF) as early as 8 days post-infection in one analysis (Valcour et al. 2012 ), although in a series of 42 acutely infected subjects 10, all in Fiebig stages I - III, CSF HIV RNA was not measurable (Hellmuth et al. 20162015). CSF escape, defined as HIV RNA above the lower limit of quantification (LLQ) in CSF when $\leq$ LLQ in blood of patients on combination antiretroviral therapy (cART) for more than 6 months, varies in prevalence between 4.4 and $13 \%$ in various surveys (Edén et al. 2010; Rawson et al. 2012; Perez Valero et al. 2012; Cusini et al. 2013; Pinnetti et al. 2014). In an observational cohort after more than 3.5 years of ART, $60 \%$ of 15 subjects maintaining virological suppression in the plasma and CSF continued to have elevated 
CSF neopterin (Edén et al. 2007), a marker of dendritic cell activation and a possible indirect sign of viral replication below the limits of assay detection. Such data was confirmed in another study using an assay that could detect down to 2.5 HIV RNA copies $/ \mathrm{mL}$, also showing a direct correlation between CSF neopterin levels and measurable HIV-1 replication (Yilmaz et al. 2008; Dahl et al. 2014). The functional magnetic resonance confirms the persistence of brain inflammation in HIV infection on ART. After 12 weeks of stable ART, 124 HIV-infected subjects had elevated myoinositol/creatinine in all brain regions and choline/creatinine in the basal ganglia and mid-frontal cortices, despite HIV RNA being undetectable in plasma in $79 \%$ of subjects and in CSF of $62 \%$ of subjects (Harezlak et al. 2011). In a study of 252 HIV-infected subjects, CSF neurofilament light chain (indicator of neuronal breakdown) decreased after ART initiation in $63 \%$ of subjects $(P<0.01)$, but remained still higher in virally suppressed subjects compared to HIV-negative controls (Jessen Krut et al. 2014). Similarly, the in vivo analysis of cell-associated HIV DNA during acute vs chronic infection, and the post-mortem analysis of brain tissue from subjects deceased for causes other than HIV while virologically suppressed, also demonstrated compartmentalization in the majority of patients, and showed that it occurs very early after estimated infection (De Oliveira et al. 2016; Lamers et al. 2016).

AQ1

AQ2

HIV-1 infection of the CNS leads to a broad spectrum of neurological syndromes, which includes dementia, mild neurocognitive disorder and asymptomatic impairment (McArthur et al. 2003; Grant et al. 2014; Watkins and Treisman 2015), establishing so called "neuroAIDS" (Sagar et al. 2014). A sub-analysis of the CHARTER cohort (Cysique and Brew 2011) showed that after 5 years of optimal viral suppression on ART, $18.1 \%$ of 116 subjects presented neuropsychological impairment, and such percentage grows to $62.8 \%$ in an Italian study (Tozzi et al. 2007) when subjects with baseline HIV-associated cognitive impairment were selected. AQ3

Altogether, these studies suggest that direct and indirect markers of CNS inflammation and damage are reduced, but not eliminated by ART, even with plasma suppression below the thresholds of detection, suggesting persistent HIV integration or in some cases ongoing low level replication within the 
CNS, thus suggesting a CNS reservoir for infection. The employment of single-genome amplification or deep sequencing has allowed better insight in the phenomenon of compartmentalization, which is the generation of locally replicating HIV subpopulations, that diverge from the circulating virus and are more resistant to therapy. Several contributions at the "Conference on Retroviruses and Opportunistic Infections (CROI) 2016" have focused on this phenomenon, correlating it with the presence of HIV Associated

Neurocognitive Disorders (HAND) before therapy (Stefic et al. 2016), poorer neurocognitive response to cART (Bowman et al. 2016), development of drug resistance patterns at virologic failure that differ from those detected in the blood (Evering et al. 2016), and transient viral escape with T-cell tropic virus or persistent viral escape with macrophage-tropic virus (Joseph et al. 2016). T-cells may be critical sources of CNS HIV in early infection (Sturdevant et al. 2015 ), however perivascular macrophages and microglia are considered to be the cells that mainly harbour HIV replication in chronic HIV infection (Schnell et al. 2011; Joseph et al. 2015). Both cell populations are long-lived, and microglia are thought not to undergo renewal from peripheral sources during an individual's life-span (Perry and Teeling 2013; Ginhoux et al. 2010 ). HIV-1 causes extensive infection of actrocytes that play an important role in the development of HIV-1 associated neurocognitive disorders. Astrocytes lack surface CD4 expression, but can internalize the virus through CD81 vesicles and thus transfect other cells, without viral replication occurring in them (Gray et al. 2014). A recent study has found that anti CXCR4 but not anti CD4 antibodies inhibit the infection of astrocytes, suggesting another mechanism for the entry of viral particles in these cells ( $\mathrm{Li}$ et al. 2016). In brain samples from patients died with HAND, $20 \%$ of astrocytes were infected, a proportion comparable to that of CD4+ T-lymphocytesT lymphocytes in the lymphoid tissue (Churchill et al. 2009), however these cells may be unable to propagate the infection (Gorry et al. 2003 ). A high concentration of infected monocytes and microglial cells supports the inflammatory escalation leading to astrogliosis and neurodegeneration in the brain, and the mechanism by which HIV-1 infected cells affect the CNS has been described in detail by S Kramer-Hämmerle et al. (2005). The mechanism involves the release of several factors of viral or cellular origin from infected glial cells, which are able to damage the CNS either by a direct interaction with neurons, or by indirectly stimulating non-infected cells to produce inflammatory and neurotoxic molecules, such as chemoattractant proteins, which call back infected or activated monocytes and lymphocytes (Fig. 1). 


\section{Fig. 1}

Mechanism of HIV-1 related damage to the central nervous system. Viral or cellular factors, released by infected and/or activated glial cells, injury the CNS either by a direct interaction with neurons or by activating the production of molecules by other uninfected cells. These factors are neurotoxic substances or chemotactic molecules, able to promote the infiltration of infiltration of infected or activated monocytes and lymphocytes into the brain. Reprinted from Virus Research (Vol. 111, Issue 2), Kramer-Hämmerle S, Rothenaigner I, Wolff H, Bell JE, Brack-Werner R "Cells of the central nervous system as targets and reservoirs of the human immunodeficiency virus", pages 194-213, Copyright (2005), with permission from Elsevier

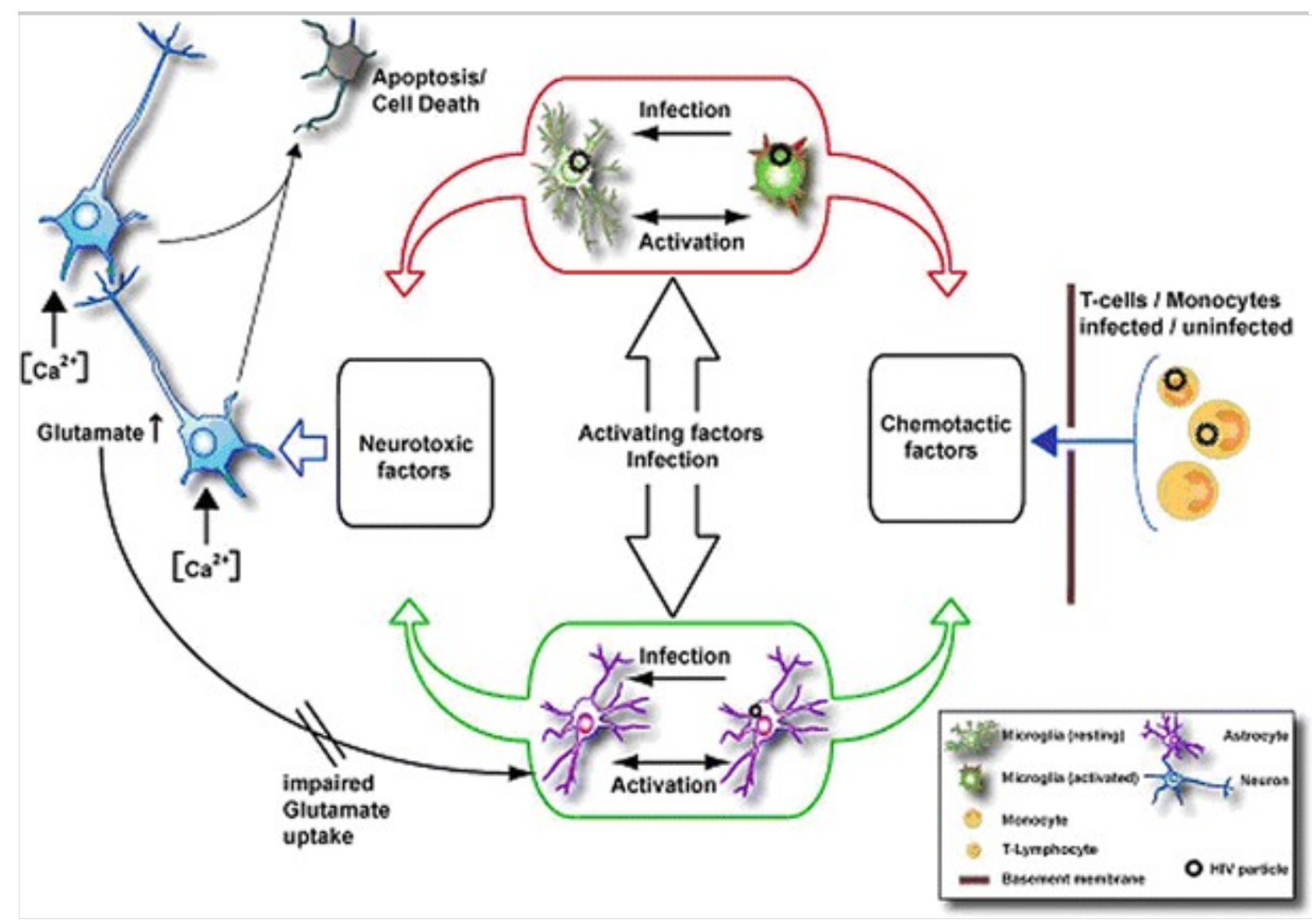

AQ4

AQ5

Thus, the CNS reservoir seems to be composed of multiple cell types within the brain parencvhima, meninges, CSF and choroids plexus (Petito et al. 1996), with variations during the natural history of the disease (i.e.: acute vs chronic vs neurologically symptomatic infection). HIV-associated neurocognitive disorders and opportunistic diseases of the CNS (i.e. multifocal leukoencephalopathy and tuberculous or cryptococcal meningitis) 
have been associated with unsatisfactory viral control (Tozzi et al. 2005) and heavily impact on patients' outcomes and quality of life (Hong and Banks 2015 ), underlying the clinical relevance of achieving an adequate control and prophylaxis of HIV-1 infection of the brain.

In this context, the low penetration of ARVs into the CNS represents a major concern. The blood-brain barrier (BBB), composed of a layer of brain microvascular endothelial cells (BMECs) supported by pericytes and astrocytes, constitutes a selective interface between the blood stream and the brain parenchyma (Zhang et al. 2015). The impermeability of the BBB to these drugs, and to most hydrosoluble drugs with a molecular weight $>400 \mathrm{Da}$ (Banks 2009), is due to: 1) the extreme tightness of endothelial junctions (50-100-fold higher than the peripheral vessels) and 2) the endothelial expression of $\mathrm{P}$-glycoprotein (P-gp), a drug efflux transporter which pumps drugs out of the cell, hampering their intracellular accumulation, in an attempt to protect the brain from xenobiotic exposure (Schinkel 1999). The direct involvement of the P-gp in the limited accumulation of ARVs into the CNS has been investigated only with protease inhibitors (PIs). A first study performed on the $m d r l a-/-$ mouse model clearly demonstrated the role of P-gp in limiting the brain concentrations of the PIs indinavir (IDV), nelfinavir (NFV) and saquinavir (SQV) (Kim et al. 1998). More recently, the involvement of P-gp in reducing ARVs' permeation into mouse brains has been also demonstrated with atazanavir (ATV) (Robillard et al. 2014).

Recently, nanotechnology has been demonstrated to be a promising strategy for improving the availability of ARVs to the CNS, and several nanostructured delivery systems have been developed to properly direct these drugs into the sanctuary site, escaping the physiological mechanisms of the BBB. The aim of this review is to provide an overview of current nanotechnological approaches to deliver ARVs into the CNS.

\section{Steps towards HIV-1 eradication}

HIV-1 latency in cells is mainly, but perhaps not only, established in infected resting memory $\mathrm{CD} 4+\mathrm{T}$ cellsCD4 $+\mathrm{T}$ cells, which account for 1 in $10^{6}$ resting CD4+T-cellsCD4+ T cells (Fletcher et al. 2014), and multiple mechanisms seem to cooperate to establish and maintain latency. Among them perhaps the most important role is played by interference on gene expression at the site of integration and the effect of repressive chromatin (Shan et al. 2011; Hakre et al. 2011). Research in the field of eradication is currently focusing on small 
molecules called latency reversing agents, that probably need to act in association with cART, selectively reactivating HIV proliferation in latently infected cells. They include histone deacetylase inhibitors (Rasmussen et al. 2013 ), histone methyltrasnferase inhibitors (Bouchat et al. 2012), proteinkinase C agonists (Darcis et al. 2015; Spivak et al. 2015), proteasome inhibitors (Miller et al. 2013) and toll-like receptor 7 agonists (Whitney et al. $2015)$.

\section{AQ6}

An ongoing study by the SEARCH (South East Asia Research Collaboration with Hawaii) group is currently recruiting participants to assess the effect of adjunctive telmisartan employment with ART during acute HIV infection to reduce the CNS reservoirs of HIV and lymph node fibrosis ( https://clinicaltrials.gov/ct2/show/NCT02750059), which will be evaluated in terms of CSF neopterin concentration, functional magnetic resonance spectroscopy (fMRS) imaging and inguinal lymph node biopsies. AQ7

\section{Blood-brain barrier selectivity to ARVs}

The BBB has been demonstrated to be rather impermeable to most antiretroviral drugs (Sagar et al. 2014), even if some of them can penetrate into the CNS a certain amount. An exhaustive summary of all the studies performed up to 2011 on this topic has been provided by Ene and colleagues (Ene et al. 2011). Except for nevirapine (NVP), which is the only ARV able to efficiently cross the $\mathrm{BBB}$ with a high $\mathrm{CSF} /$ plasma concentration ratio (about 0.5), all the other ARVs display negligible or low CSF concentration. Among them, the nucleoside/nucleotide reverse transcriptase inhibitors (NRTIs) zidovudine (ZDV), lamivudine (3TC), stavudine (D4T), didanosine (DDI) and abacavir (ABC) can partially cross the BBB ( $>0.06 \mathrm{CSF} /$ plasma concentration ratio), possibly due to their low molecular weight and protein binding rates. IDV shows a penetration rate into the CSF comparable to NRTIs, with a mean CSF/plasma concentration ratio equal to 0.17 (Solas et al. 2003 ). Conversely, the endothelial barrier is poorly permeable to some protease inhibitors (amprenavir (APV) and darunavir (DRV), 0.01-0.06 of $\mathrm{CSF}$ /plasma concentration ratio) and almost impermeable to others such as ritonavir (RTV), lopinavir (LPV), NFV, SQV, and ATV. The CSF concentration of non-nucleosidic reverse-transcriptase inhibitors (NNRTIs) such as efavirenz (EFV) is also very low (0.004-0.005 of CSF/plasma ratio) (Yilmaz et al. 2012), although it exceeds its IC50 value in wild-type HIV and 
is therefore sufficient to exert a therapeutic activity in the brain (Best et al. 2011). The inhibitor of CCR5 co-receptors maraviroc (MVC) (Yilmaz et al. 2009 ), the integrase strand transfer inhibitor (INSTI) raltegravir (RGV) (Letendre et al. 2009) and the NRTI tenofovir (TDF) (Best et al. 2012) are all able to reach the CSF in low but detectable amounts $(0.038,0.056$ and 0.057 $\mathrm{CSF} /$ plasma concentration ratio, respectively). Finally, BBB penetration by the fusion inhibitor enfuvirtide (ENF) is totally negligible (Price et al. 2008).

Figure 2 summarizes the rank order of ARVs penetration across the BBB.

\section{Fig. 2}

Permeability rank order of ARVs across the BBB. The rate of permeation, calculated as $\mathrm{CSF} /$ plasma concentration and graphically represented by arrows width, is: nevirapine (NVP) > zidovudine (ZDV), lamivudine (3TC), stavudine (D4T), didanosine (DDI), abacavir (ABC), indinavir (IDV) $>$ amprenavir (APV), darunavir (DRV), maraviroc (MVC), raltegravir (RGV), tenofovir $(\mathrm{TDF})>$ ritonavir $(\mathrm{RTV})$, lopinavir (LPV), nelfinavir (NFV), saquinavir (SQV), atazanavir (ATV), efavirenz (EFV). Enfuvirtide (ENF) concentration in CSF is undetectable. BMEC: brain microvascular endothelial cell

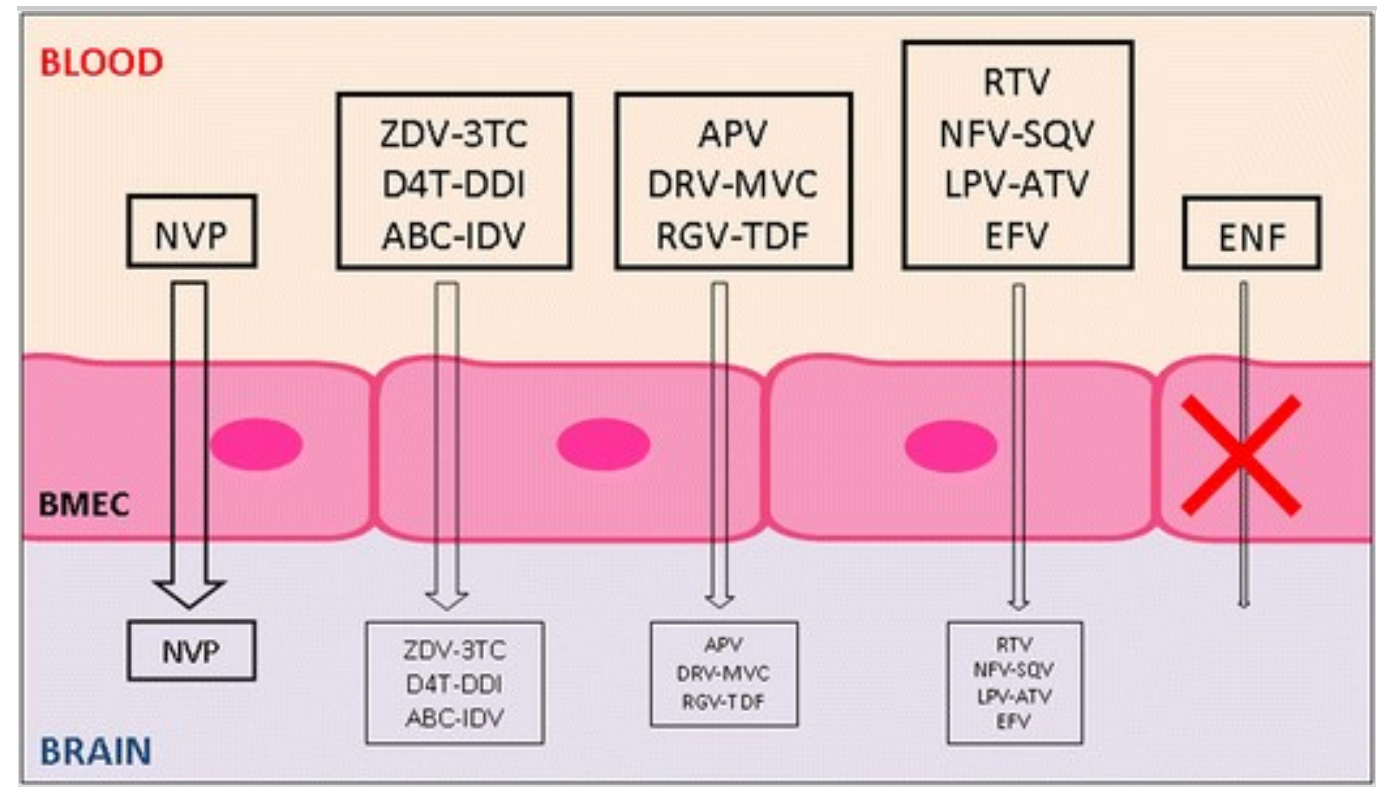

\section{Nanoparticles for drug delivery}

The main pharmacological factors influencing drug delivery to the brain are lipophilicity, molecular weight and charge, chemical structure and conformation, systemic absorption, affinity for receptors, efflux proteins and carriers, clearance rate, dissolution rate and particle size flexibility and permeability. Approaches to increase drug permeability have been 
lipidization, research on prodrugs, enzymatic physicochemical, site-specific enzyme-activated and receptor-based chemical drug-delivery systems, and molecular packaging, but all these strategies have limitations (Lu et al. 2014).

In the last fifteen years, nanotechnology has provided a generation of organic and inorganic nanoparticles (NPs) with the aim of optimizing diagnostic and therapeutic applications in various biomedical fields. Regarding drug delivery, nanoformulation can offer some key advantages, such as an improved blood half-life and bioavailability, a higher aqueous stability, and a precise delivery due to functionalization with targeting moieties, reducing the administered dose and the dose-related side effects. The peculiar physicochemical features of inorganic nanoparticles (i.e. iron oxide, gold or manganese NPs), make them the best candidates for photothermal or radiation therapy (Cooper et al. 2014; Cherukula et al. 2016) as well as tumor hypertermia (Kobayashi 2011 ), and imaging for cancer (Corot and Warlin 2013), inflammatory (Wu et al. 2016) and infectious diseases (Chi et al. 2012). Moreover, the characteristic properties of these NPs allow them a contemporary diagnostic and therapeutic application, resulting in them being powerful theranostic tools (Corsi et al. 2011; Gobbo et al. 2015). Although different types of inorganic NPs have been investigated as drug delivery systems (Paciotti et al. 2004; Wang et al. 2015), to date organic NPs have shown the most exciting applications in therapeutics delivery. Some nano-products, mainly devoted to cancer management, are now FDA-approved or under various stages of clinical study, and the liposomal and polymeric NPs are the most represented (Mitragotri and Stayton 2014).

For brain delivery, different classes of NPs have been identified as valid tools for driving drugs to the CNS. Some examples are reported in Table 1. A major role is played by lipidic NPs (liposomes and solid lipid nanoparticles). The chemical-physical features of lipidic NPs allow them to easily cross the BBB (Kaur et al. 2008; Lai et al. 2013), and their capability of reaching the CNS is further increased by surface engineering with BBB targeting moieties (Re et al. 2011; Singh et al. 2016) or cell-penetrating peptides (CPPs) (Qin et al. 2012). Lipidic NPs have the advantage of being non-toxic and biodegradable, since they are made of naturally occurring compounds. Moreover, liposomal encapsulation of drugs avoids their degradation and reduces the possible systemic toxicity of loaded drugs. On the other hand, their use is limited by their low storage stability and encapsulation efficiency, together with a rapid leakage of hydrosoluble molecules. Polymeric NPs, 
properly modified to obtain an effective passive or active trans-BBB permeability, were also profoundly investigated for drug delivery to the CNS (Kreuter 2014; Saucier-Sawyer et al. 2015; Vilella et al. 2015). Among them, surfactant-coated nanoparticles, which represent the most investigated models (Steiniger et al. 2004; Petri et al. 2007; Wilson et al. 2008; Sun et al. 2015 ), are able to drive drugs across the BBB by exploiting the adsorption of low density lipoproteins (LDL) from blood plasma onto the nanoparticle surface and the interaction with the LDL receptors on the plasma membrane of the endothelial cells. Polymeric NPs, as lipidic NPs, are characterized by a high biocompatibility, biodegradability and loading capability. In addition, these nanoparticles are water-soluble, show an efficient controlled release profile, and their synthesis is simple and inexpensive. Several studies have been aimed at improving the trans-BBB permeation of magnetic NPs, exploiting encapsulation in polymeric or liposomal shells, or the application of an external magnetic field, or surface modification with ligands directed against receptors expressed on the apical membrane of endothelial cells (Qiao et al. 2012; Thomsen et al. 2015; Busquets et al. 2015). Other inorganic NPs were designed to pass through the BBB, exploiting enhanced endothelial permeability allowed by surface functionalization. Small sized silica NPs have been demonstrated to cross the BBB in vitro and in vivo upon surface modification with polyethylene glycol (PEG) (Liu et al. 2014). Gold nanoparticles are able to cross the barrier when conjugated to CPPs, resulting in improved delivery of anticancer drugs and contrast agents to brain gliomas (Cheng et al. 2014). Finally, some studies demonstrated the employment of functionalized quantum dots for crossing the BBB; these were mainly focused on the delivery of HIV-targeted drugs (Xu et al. 2013), as reported below. Despite the advantage of inorganic NPs being able to combine drug delivery functions with multimodal imaging capabilities, a limitation in their biomedical employment is related to toxicity concerns about these nanomaterials. Much data is currently available about this topic, but much more effort is still required to completely elucidate this issue, starting with the different physicochemical and physiological factors behind the interaction of NPs with biological systems (Choi et al. 2013). Recent advances have been directed at reducing toxicity of inorganic NPs, mainly by controlling particle size and surface coating and therefore, optimizing their biodegradation and pharmacokinetic features (Ehlerding et al. 2016). 


\section{Table 1}

Overview of nanoparticles for the drug delivery across BBB

\begin{tabular}{|c|c|c|c|}
\hline $\begin{array}{l}\text { Nanoparticle } \\
\text { type }\end{array}$ & Drug & $\begin{array}{c}\text { Experimental } \\
\text { model }\end{array}$ & Nano-compound \\
\hline \multirow{8}{*}{$\begin{array}{l}\text { Lipidic } \\
\text { nanoparticles }\end{array}$} & $\begin{array}{l}\text { Derivative of } \\
5 \text {-Fluorouracil } \\
(\mathrm{FU})\end{array}$ & In vivo model & $\begin{array}{l}\text { DO-FUdR-solid lipid } \\
\text { NPs (Wang et al. 2002) }\end{array}$ \\
\hline & Doxorubicin & In vivo model & $\begin{array}{l}\text { stearic acid-PEG } \\
\text { 2000-solid lipid NPs } \\
\text { (Zara et al. 2002) }\end{array}$ \\
\hline & Nitrendipine & In vivo model & $\begin{array}{l}\text { Solid lipid NPs } \\
\text { (Manjunath and } \\
\text { Venkateshwarlu 2006) } \\
\text { AQ8 }\end{array}$ \\
\hline & Daunorubicin & $\begin{array}{l}\text { Glioma cells, in } \\
\text { vitro BBB model } \\
\text { and in vivo model }\end{array}$ & $\begin{array}{l}\text { MAN-liposomes-Tf } \\
\text { (Ying et al. 2010) }\end{array}$ \\
\hline & Doxorubicin & $\begin{array}{l}\text { Glioma cells and } \\
\text { in vivo model }\end{array}$ & $\begin{array}{l}\text { Lf-procationic } \\
\text { liposomes (Chen et al. } \\
2011)\end{array}$ \\
\hline & $\begin{array}{l}\text { Curcumin } \\
\text { derivative }\end{array}$ & $\begin{array}{l}\text { In vitro } \mathrm{BBB} \\
\text { model }\end{array}$ & $\begin{array}{l}\text { ApoE-liposomes (Re et } \\
\text { al. 2011) }\end{array}$ \\
\hline & - & $\begin{array}{l}\text { Brain capillary } \\
\text { endothelial and } \\
\text { glioma cells }\end{array}$ & $\begin{array}{l}\text { TAT/D-TAT/R8- } \\
\text { liposomes (Qin et al. } \\
\text { 2012) }\end{array}$ \\
\hline & Docetaxel & $\begin{array}{l}\text { Glioblastoma cells } \\
\text { and in vivo model }\end{array}$ & $\begin{array}{l}\text { Lf-solid lipid NPs } \\
\text { (Singh et al. 2016) }\end{array}$ \\
\hline \multirow[t]{2}{*}{$\begin{array}{l}\text { Polymeric } \\
\text { nanoparticles }\end{array}$} & Doxorubicin & In vivo models & $\begin{array}{l}\text { PS } 80 / \text { P188-coated } \\
\text { PBCA NPs (Steiniger et } \\
\text { al. 2004; Petri et al. } \\
\text { 2007) }\end{array}$ \\
\hline & Loperamide & In vivo model & $\begin{array}{l}\text { g7-PLGA NPs (Tosi et } \\
\text { al. 2007) }\end{array}$ \\
\hline
\end{tabular}

Abbreviations: NPs nanoparticles, MNPs magnetic nanoparticles, PLA poly(lactic acid), $P E G$ poly ethylenglycol, $P L G A$ poly(lactide-co-glycolide), $P B C A$ poly(butyl cyanoacrylate), $p(H P M A)$-co- $p(L M A) \mathrm{p}$ (2-hydroxypropyl-methacrylamide)co-p(laurylmethacrylate) amphiphilic copolymer, $B C N U$ 3-bis(2-chloroethyl)1-nitrosourea, $D O-F U d R$ 3',5'-dioctanoyl-5-fluoro-2'-deoxyuridine, $A d$ adenosine, $A p$ DNA aptamer, ApoE apolipoprotein E, HPG hyperbranched polyglycerol, PS80 polysorbate $80, P 188$ poloxamer $188, T f$ transferrin, $L f$ lactoferrin, $M A N$ p-aminophenyl- $\alpha$-D-mannopyranoside, TAT Cys-AYGRKKRRQRRR, $D$-TAT Cys-RKARYRGRKRQR, R8 Cys-RRRRRRR, $g 7 \mathrm{H}_{2} \mathrm{~N}-\mathrm{Gly}-\mathrm{L}-\mathrm{Phe}-\mathrm{D}-\mathrm{Thr}-\mathrm{Gly}$-LPhe-L-Leu-L-Ser(O- $\beta$-D-Glucose)-CONH 2

${ }^{\mathrm{a}}$ In the presence of an external magnetic force 


\begin{tabular}{|c|c|c|c|}
\hline \multirow[t]{7}{*}{$\begin{array}{l}\text { Nanoparticle } \\
\text { type }\end{array}$} & Drug & $\begin{array}{c}\text { Experimental } \\
\text { model }\end{array}$ & Nano-compound \\
\hline & Rivastigmine & In vivo model & $\begin{array}{l}\text { PS80-coated PBCA NPs } \\
\text { (Wilson et al. 2008) }\end{array}$ \\
\hline & Paclitaxel & $\begin{array}{l}\text { Glioma cells and } \\
\text { in vivo model }\end{array}$ & $\begin{array}{l}\text { Ap-PEG-PLGA NPs } \\
\text { (Guo et al. 2011) }\end{array}$ \\
\hline & Domperidone & In vivo model & $\begin{array}{l}\text { p(HPMA)-co-p(LMA) } \\
\text { NPs (Hemmelman et al. } \\
2011)\end{array}$ \\
\hline & BCNU & In vivo model & $\begin{array}{l}\text { Tf-PLA (Han et al. } \\
\text { 2012) }\end{array}$ \\
\hline & Acetylpuerarin & In vivo model & $\begin{array}{l}\text { PS80-coated PLGA NPs } \\
\text { (Sun et al. 2015) }\end{array}$ \\
\hline & Camptothecin & $\begin{array}{l}\text { Brain capillary } \\
\text { endothelial and } \\
\text { glioblastoma cells, } \\
\text { and in vivo model }\end{array}$ & $\begin{array}{l}\text { PLA-HPG-Ad NPs } \\
\text { (Saucier-Sawyer et al. } \\
2015 \text { ) }\end{array}$ \\
\hline \multirow{5}{*}{$\begin{array}{l}\text { Inorganic } \\
\text { nanoparticles }\end{array}$} & Paclitaxel & $\begin{array}{l}\text { Glioma cells and } \\
\text { in vivo model }\end{array}$ & $\begin{array}{l}\text { MNPs (Zhao et al. } \\
2010)^{\mathrm{a}}\end{array}$ \\
\hline & - & $\begin{array}{l}\text { In vitro BBB } \\
\text { model and in vivo } \\
\text { model }\end{array}$ & $\begin{array}{l}\text { Lf-PEG-coated } \mathrm{Fe}_{3} \mathrm{O}_{4} \\
\text { NPs (Qiao et al. } 2012 \text { ) }\end{array}$ \\
\hline & Doxorubicin & $\begin{array}{l}\text { Glioma cells and } \\
\text { in vivo model }\end{array}$ & $\begin{array}{l}\text { TAT-gold NPs (Cheng et } \\
\text { al. 2014) }\end{array}$ \\
\hline & - & $\begin{array}{l}\text { In vitro BBB } \\
\text { model and in vivo } \\
\text { model }\end{array}$ & $\begin{array}{l}\text { PEG-Silica NPs (Liu et } \\
\text { al. 2014) }\end{array}$ \\
\hline & - & $\begin{array}{l}\text { In vitro BBB } \\
\text { model }\end{array}$ & $\begin{array}{l}\text { Tf-MNPs-loaded } \\
\text { liposomes (Ding et al. } \\
2014)^{\mathrm{a}}\end{array}$ \\
\hline \multicolumn{4}{|c|}{$\begin{array}{l}\text { Abbreviations: } N P \text { s nanoparticles, } M N P S \text { magnetic nanoparticles, } P L A \text { poly(lactic } \\
\text { acid), } P E G \text { poly ethylenglycol, } P L G A \text { poly(lactide-co-glycolide), } P B C A \text { poly(butyl } \\
\text { cyanoacrylate), } p(H P M A)-c o-p(L M A) \text { p(2-hydroxypropyl-methacrylamide)- } \\
\text { co-p(laurylmethacrylate) amphiphilic copolymer, } B C N U \text {-bis(2-chloroethyl)- } \\
\text { 1-nitrosourea, } D O-F U d R 3^{\prime}, 5^{\prime} \text {-dioctanoyl-5-fluoro-2'-deoxyuridine, } A d \text { adenosine, } \\
\text { Ap DNA aptamer, } A p o E \text { apolipoprotein E, } H P G \text { hyperbranched polyglycerol, } P S 80 \\
\text { polysorbate } 80, P 188 \text { poloxamer } 188, T f \text { transferrin, } L f \text { lactoferrin, } M A N \\
\text { p-aminophenyl- } \alpha \text {-D-mannopyranoside, } T A T \text { Cys-AYGRKKRRQRRR, } D-T A T \\
\text { Cys-RKARYRGRKRQR, R8 Cys-RRRRRRR, } g 7 \mathrm{H}_{2} \text { N-Gly-L-Phe-D-Thr-Gly-L- } \\
\text { Phe-L-Leu-L-Ser(O- } \beta-D-G l u c o s e)-C O N H\end{array}$} \\
\hline \multicolumn{4}{|c|}{${ }^{\mathrm{a}}$ In the presence of an external magnetic force } \\
\hline
\end{tabular}

\section{Candidate ARVs for nanoformulation}


Provided that HIV-infected subjects harboring drug-resistant viral strains do not have standardized needs for therapy, but rather their choice is constrained by resistance, and therefore it is desirable that the widest number of antiretrovirals be nanoformulated to reach the CNS, there are some drugs and drug classes that are particularly promising and others that show neurologic tolerability problems. NRTIs are a widely differentiated class, in which 3TC, emtricitabine (FTC), ABC and TDF are not associated to neurologic adverse events. Moreover, such drugs have proven to be the most effective backbone on sensitive HIV-1 strains and very active on brain macrophages (Senanayake et al. 2015). Protease inhibitors, the class that revolutioned the antiretroviral therapy, today appear weaker in comparison to some NNRTIs (Bonora et al. 2009 ) and to INSTIs (Molina et al. 2015). Moreover, PIs more than other compounds are associated to the formation of 2'LTR circles and to the reduction of inflammation upon intensification with $\mathrm{RGV}$, an indirect sign of persistent viral replication (Buzón et al. 2010; Massanella et al. 2014). On the other side, among NNRTIs, EFV and to a lower extent rilpivirine show some degree of neurologic and psychiatric side effects (Mills et al. 2013). Among INSTIs, RGV can cause headache, reported between 2.2 and $16.1 \%$ of recipients in phase 2-3 studies (Temesgen and Siraj 2008) and also dolutegravir (DTG) is associated to headache and insomnia in clinicals (Kandel and Walmsley 2015). However, a RGV-based intensification strategy is in progresshas been recently completed to reduce the persistent immunoactivation within the CNS, which may hypothetically lead to long-term brain damage in the presence of minimal viral replication, and results are awaited soon ( https://clinicaltrials.gov/ct2/show/NCT00672932). Another ongoing study is evaluating the effect of switching stably suppressive EFV to RGV, in combination with a TDF/FTC backbone, on CNS biological changes, detected through neuroimaging ( https://clinicaltrials.gov/ct2/show /NCT01978743 ). Investigators are using fMRS to measure changes in brain neurometabolites associated to long-term EFV and to the switch to RGV, looking for a correlation with modifications in cognition assessed by Trail Making and Digit Substitution Tests, and with changes in emotion and sleep quality. In the near future, a further study is expected to compare CNS effects in the switch from EFV to DTG, based on clinical evidences and not on the use of questionnaires ( https://clinicaltrials.gov/ct2/show/NCT02285374 ). Among the biologic drugs, i.e. drugs that may be able to modulate the immune response in the brain, only dimethyl fumarate has been hypothesized as a possible option, but to date no clinical studies have been planned (Gill and Kolson 2013). 


\section{ARVs nanoformulation to overcome the blood-brain barrier}

To prevent neuroAIDS nanotechnology has been intensely explored, with the aim of developing novel and promising drug delivery systems in order to improve the ability of ARVs to reach the CNS at suitable amounts to allow them to suppress viral replication in this sanctuary site. Several experimental attempts have been carried out in recent years in order to increase the BBB permeability for antiretroviral drugs (Fig. 3).

\section{Fig. 3}

Different types of nanoformulations employed to deliver ARVs across the BBB. Non-specific delivery strategies have been employed, based on liposomes, CPPs, PLGA NPs, PMA-coating metallic NPs and nanoART, for the delivery of ritonavir (RTV), saquinavir (SQV), atazanavir (ATV), lamivudine (3TC), tenofovir (TDF), foscarnet (PFA), enfuvirtide (ENF), azidothymidine (AZT), lopinavir (LPV), efavirenz (EFV) and azidothymidine 5-triphosphate (AZTTP). A macrophage-mediated permeation of the BBB has been studied with nanoART loaded with ATV, RTV and indinavir (IDV). Actively targeted NPs has been developed for the delivery of SQV, AZT, stavudine (D4T), and delavirdine (DLV). BMEC: brain microvascular endothelial cell 


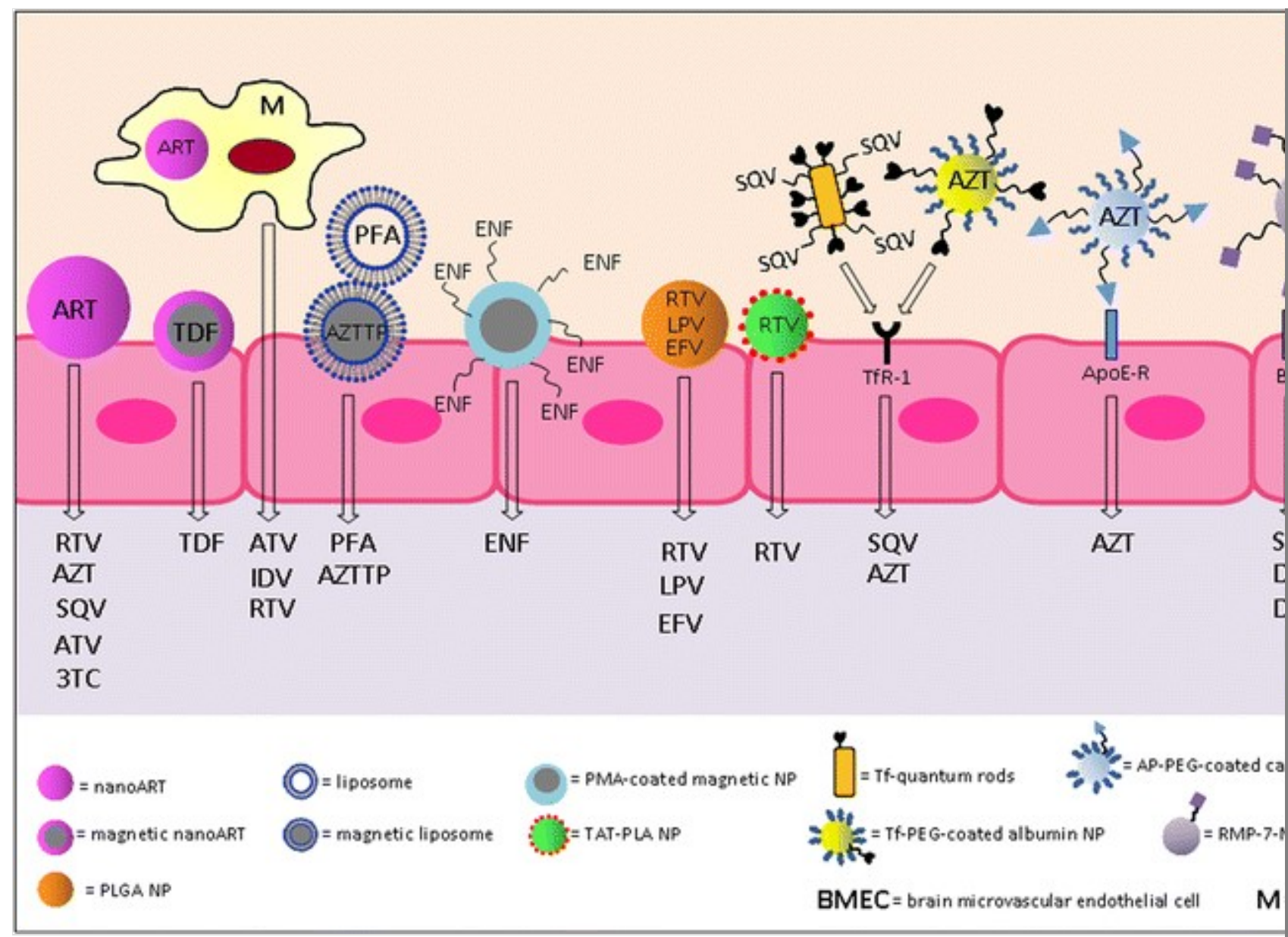

\section{Liposomes}

As introduced above, a great effort has been made to design an effective NP for drug delivery to the brain, with lipidic NPs and, in particular, with liposomes. A liposome-based nanoformulation of foscarnet (PFA), an antiviral drug mainly used for treatment of cytomegalovirus (CMV) infections but also employed in combination with other ARVs in HIV-1 selvage therapy (Canestri et al. 2006; Delory et al. 2015), was demonstrated to increase by 13 times its brain accumulation in rats compared to the soluble free drug (Dusserre et al. 1995 ). However, liposomes are characterized by a short half-life because they tend to be sequestered by the reticuloendothelial system, and their encapsulation is particularly inefficient with water-soluble drugs (Torchilin 2005 ). A more appealing application of these NPs has been investigated with magnetic liposomes composed of phosphatidyl choline-cholesterol and magnetite, and encapsulated with azidothymidine 5-triphosphate (AZTTP), the active form of zidovudine, also named azidothymidine (AZT) (Saiyed et al. 2010). Interestingly, these nanocompounds demonstrated a 3-fold higher permeability through the BBB compared to free drugs, due both to direct transmigration and to monocyte-mediated transport; in both cases, the presence of an external magnetic field guided the permeation of the BBB 
(Saiyed et al. 2010).

\section{NanoART}

In 2009In 2009, Nowacek and Gendelman 2009 described how ARVs nanoformulated with different surfactants and by different methodological approaches ("nanoART") could be engaged to improve drug permeability into the brain. A study from Kuo and Chen (2006) demonstrated how incorporation of AZT and 3TC into polybutylcyanoacrylate (PBCA) and methylmethacrylate-sulfopropylmethacrylate (MMA-SPM) nanoparticles increased their permeability across the BBB, through absorptive endocytosis by endothelial cells. In subsequent research, the same authors developed a cationic solid lipid nanoparticle (CSLN) for SQV encapsulation, stabilized with polysorbate 80 and composed of nonionic Compritol 888 ATO and cacao butter in a lipid core center, and cationic stearylamine and dioctadecyldimethyl ammonium bromide in the core periphery. This nanoART showed a high entrapment efficiency and optimal release kinetics of SQV, being a valid tool for transport of ARVs across the BBB (Kuo and Chen 2009). The nanoformulation of IDV in a Lipoid E80-based nanoART allows prompt absorption and release by human monocyte-derived macrophages (MDM), with a sustained anti-retroviral activity in these cells (Dou et al. 2007). This strategy has been exploited to deliver IDV-NP, loaded into bone marrow macrophages (BMM), across the BBB. After injection of IDV-NP-BMM in mouse models of HIV-1 encephalitis, the IDV was readily detected in the brain and specifically in encephalitic subregions, where a significant antiretroviral activity was also observed (Dou et al. 2009). AQ14

More recently, ATV and RTV crystalline nanoART formulated with poloxamer- 188 by high-pressure homogenization, have been demonstrated to exert a protective role in the infected brain sub-regions of mice (Dash et al. 2012). Moreover, ATV-, RTV-, IDV- and EFV-based nanoART exploit monocyte-derived macrophages as "Trojan horses" to enter brain BMECs. This strategy, involving a cell-to-cell contact between macrophages and brain endothelium, resulted in a highly efficient passage of ATV and RTV across the BBB in vivo, with a penetration into the CNS up to 4-fold higher with folate-coating of nanoART (Kanmogne et al. 2012). In a recent study, magnetic nanoART has been developed by assembling anti-HIV drugs around an ultrasmall iron oxide NP, using a magnetically guided layer-by-layer (LbL) technique. The LbL technique allowed co-loading of TDF and vorinostat 
(latency-breaking agent). This nanodrug has shown a sustained drug release of up to 5 days, with an acceptable BBB transmigration (about $38 \%$ ) and a decrease of p24 levels in $33 \%$ of infected human astrocytes (Jayant et al. 2015 ).

\section{TAT-NPs}

The use of CPPs as carriers of therapeutic agents across the BBB is also promising. Indeed, this class of peptides, which can be internalized by cells through mechanisms still not completely clarified, presents some evident advantages; such as a simple synthesis, a high internalization rate and a low cytotoxicity. Nevertheless, in vivo application of CPP is limited by its lack of specificity in targeting cells and its accumulation in off-target cells (Jafari et al. 2015 ). Among CPPs, the cationic trans-activating transcriptor (TAT) peptide is one of the most used to enhance trans-BBB permeation capability. In 2008, Rao et al. showed that TAT-Poly-L-lactide (PLA) nanoparticles loaded with RTV significantly improved the trans-BBB delivery of the drug in mouse models. This strategy allowed it to escape the P-glycoprotein efflux action, with a 800-fold higher RTV level in the brain after 2 weeks of treatment. Moreover, the BBB integrity was not disrupted and therefore, a transcytotic mechanism typical of TAT-conjugated cargoes has been suggested to explain RTV permeation across brain endothelium.

\section{Actively targeted NPs}

Another research trend has highlighted the importance of active targeting for an effective drug delivery into the CNS. Exploiting the over-expression of the transferrin receptor-1 (TfR-1) on the apical side of the BBB endothelium (Jefferies et al. 1984), some studies reported the conjugation of transferrin (Tf) to quantum rods to obtain a smart delivery system of drugs into the CNS through TfR-1 binding ( $\mathrm{Xu}$ et al. 2008). This strategy enhanced the trans-BBB permeation of SQV in vitro, increasing its antiviral activity on infected peripheral blood mononuclear cells cultured at the basolateral end of the BBB model (Mahajan et al. 2010). Transferrin functionalization has also been employed to optimize albumin-based NPs coated with PEG and containing AZT. A significant increase in rat brain delivery of AZT was obtained in transferrin-functionalized NPs compared to nude NPs (Mishra et al. 2006). The main role of active targeting to localize NPs into the CNS has been confirmed by Kuo and Lee (2012), who have exploited another BBB target, the bradykinin type II receptor (B2-R), to design a methylmethacrylate- 
sulfopropylmethacrylate nanoparticle functionalized with the bradykinin analogue RMP-7. This nanodevice increased the permeation of D4T, SQV and delavirdine (DLV) across the BBB, exploiting both a direct target-receptor interaction and an enhanced paracellular flux through tight junctions between the brain microvascular endothelial cells (Kuo and Lee 2012).

An actively targeted NP has been also developed by Gerson et al. (2014) to optimize the brain accumulation of AZT. The encapsulation of this ARV into cationic nano-gels functionalized with PEG and with a peptide (AP) binding brain-specific apolipoprotein E receptors (ApoE-R), induced a 10-fold suppression of HIV-1 activity in the brain of infected mice, significantly lower activity compared to that with free AZT.

Active targeting of NPs by conjugation of BBB receptors is particularly promising, since this would provide direct internalization of ARVs into the BMECs. Furthermore, active targeting is expected to reduce sequestration of nanodrugs by off-target organs with improved bioavailability in the CNS, adding a clear benefit to pharmacokinetics of brain-targeted ARVs. The only concern with active targeting would be that identification of more specific targets of BBB is needed to exploit proper drug delivery. In this sense, it is important to highlight that some receptors, such as the TfR-1 of the bradykinin type II receptors, are overexpressed in various physiological systems or in pathological conditions such as cancer, while ApoE receptors are actually brain-specific.

\section{Polymer-based NPs}

In 2010, Destache and co-workers demonstrated the ability of poly(dl-lactideco-glycolide) (PLGA) nanoparticles to increase the peak concentrations of RTV, LPV and EFV in the brains of mice injected with the nanoformulated ARVs in respect to those observed for the mice injected with the free drugs. Freely injected ARVs did not achieve a concentration of $1 \mu \mathrm{g} / \mathrm{g}$ in brain, while nanoformulated drugs reached concentrations higher than $5 \mu \mathrm{g} / \mathrm{g}$ in this tissue. A longer period of detection of LPV, up to 35 days post-injection of the single dose, was also observed in the brain, upon formulation with PLGA NPs (Destache et al. 2010).

Recently, it has been reported that even ENF, whose low permeation across the BBB is mainly due to its molecular size and complex structure, can significantly pass through the barrier upon conjugation with iron oxide NPs 
coated with the amphiphilic PMA polymer (Fiandra et al. 2015). By a multidisciplinary in vitro and in vivo approach, it has been suggested that the translocation of nanoformulated ENF across the BBB was possible through the absorption of the PMA-coated NPs on the apical membrane of the BMECs, resulting in a passive internalization of the nano-ENF, an intracellular release of the drug upon degradation of the nanocompex into the endosomal pathway and, ultimately, an efflux of ENF into brain parenchyma (Fiandra et al. 2015). The charm of this strategy was that the PMA polymer was absorbed into microvascular endothelial cells, and then promptly degraded by the endosomal system to release free ENF, which then could easily pass through the basolateral side of the cells to reach the CNS. This is a very relevant point, since various studies have demonstrated that nanoformulation improves drug delivery through the $\mathrm{BBB}$, but the proper release kinetics of the free drug after passing the barrier to ensure antiretroviral activity has been much less investigated.

\section{Conclusions}

Suboptimal drug concentration in the brain represents the main limiting step for HIV eradication from this sanctuary. An adequate drug concentration for antiretrovirals in the CSF is not given in guidelines, but has generally been defined as being above the IC50 and IC90. This goal is achieved at lower levels than those obtained in plasma, since protein binding in the CSF is negligible (Croteau et al. 2013; Di Yacovo et al. 2015) and currently the presence of CSF levels comparable to unbound plasma levels is considered a marker of efficacy (Letendre et al. 2014). However, the main limitation is that drug concentrations in the CNS tissues are not known and also the degree of virologic suppression in macrophages cannot be measured.

Different types of nanoparticles have been identified as valid tools to increase drugs targeting to the brain by exploiting passive or active internalization of the nanoparticles in the BBB endothelium. More specifically, nano-ARVs penetration into the CNS was achieved by passive permeation across BBB (i.e. liposomes and polymeric NPs with amphiphilic properties or coated of surfactants), also associated to P-glycoprotein efflux escaping (i.e. RTV-TAT-PLA NPs), or exploiting the active interaction of ligands on NP surface (Tf, RMP-7, AP) with specific receptors on BMECs luminal membrane. All these nano-technological approaches resulted somewhere efficient in favoring ARVs delivery to the CNS. In terms of the ideal candidate to be nanocomplexed for an efficient CNS penetration, a good 
balance between drug efficiency and neurological safety should be attained. However, this strategy may be applied to all classes of ARVs, so that patients infected with drug-resistant strains may benefit from it.

An important aspect of studying penetration of nano-ARVs and their antiviral effects in the brain deals with the choice of the appropriate animal model. While mice and rats are generally preferred to evaluate brain targeting and accumulation (Dusserre et al. 1995; Mishra et al. 2006; Rao et al. 2008; Destache et al. 2010; Fiandra et al. 2015), humanized mice are the most commonly used animal for HIV research together with non-human primates (Policicchio et al. 2016). Humanized mice have a great translational power, since they give the opportunity to investigate human biological processes in vivo and develop pre-clinical assessment of drugs and human-cell-based therapeutics before progression to clinic (Denayer et al. 2014). Beyond human tumor xenografts mainly directed to oncological studies, the most commonly used humanized mice are those that mimic the human immune system. Among the numerous applications of these models, the study of pathogenesis of human-specific infectious agents and its treatment deserve attention. The development of new drugs towards infectious diseases, including those aimed to regulate HIV activation and replication, took advantage from using infected humanized mice (Shultz et al. 2007; Singh et al. 2014), and all studies aimed to elucidate the antiretroviral efficiency of nanoformulated antiretroviral drugs also exploited these experimental models (Dou et al. 2009; Gerson et al. 2014; Dash et al. 2012; Kanmogne et al. 2012).

Finally, we should remember that optimization of delivery of ARVs into the CNS by nanoformulation, while important for abolishing residual viral replication in this site with a likely impact on the control of HIV-associated neurocognitive disorders, is insufficient per se to achieve total eradication of the virus. Destroying integrated HIV-1 in latently infected cells requires different strategies and drugs; among others, some strategies need to address CD4+ T-cellsCD4+ T cells in the lymphoid tissue, but this field still offers more questions than answers (Kimata et al. 2016). Moreover, other biological barriers are likely to protect other sanctuaries, such as the blood-testis barrier, although the HPTN 052 study results seem to minimize the risks associated to this reservoir (Grinsztejn et al. 2014). In this setting, studies on the CNS penetration of nanoformulated compounds should also take into account the male genital tract compartment, as some authors are doing (Robillard et al. 
2014 ). Lymph node barrier is more a functional barrier made of different types of cellular sanctuaries that could be faced by conjugating ARVs to anti-CD4- nanoparticles (Corsi et al. 2016).

So, which is the real impact of CNS reservoir on the possibility to eradicate or 'functionally cure' the HIV-1 infection? 'Functional cure', that is the ability to suppress HIV replication for years after treatment withdrawal, has been documented so far for the Mississippi baby (Luzuriaga et al. 2015), who remained viremia-free for 2 years, and for the Visconti cohort (Sáez-Cirión et al. 2013 ), in which the longest control described is 12 years, always in a subject infected since birth, without specific strategies targeting the brain, apart from the choice of antivirals with fair penetration in the CNS. However, the fact that this has been achieved only in a neonatal setting, when the blood-brain barrier is still permeable, or at the very beginning of HIV-1 infection (4-10 weeks after infection), when the CNS may not have been colonized yet or the infection may still be confined to T-lymphocytes trafficking across the $\mathrm{BBB}$, seems to support rather than to deny the importance of the CNS reservoir. The only subject who has been cured from $\mathrm{HIV}$ at present, the Berlin patient, was not in acute infection and did not receive treatment specifically targeted. A double blind, placebo controlled crossover study is starting to evaluate whether the addition of atorvastatin to a suppressive antiretroviral regimen has the potential of down-modulating cerebral monocytes' activation in subjects with HIV-associated dementia, ( https://clinicaltrials.gov/ct2/show/NCT01600170 ) measuring CNS immune activation markers and neurocognitive function and defining gene expression patters of monocyte activation before and following statin treatment.

AQ15

AQ16

However, one further problem is that our diagnostics is currently poor in helping us monitor these approaches, and biological imaging that may show where and how much virus hides in tissues when blood tests show optimal clearance is slowly moving its initial steps (Eck et al. 2010; Chen et al. 2014 ). To conclude, we seem to be still distant from the possibility of totally eradicating HIV, but addressing functional and anatomical reservoirs with a nanotechnology-based diagnostic and therapeutic approach is mandatory.

\section{Compliance with ethical standards}

Conflict of interest The authors declare that they have no conflict of 
interest.

\section{References}

Banks WA (2009) Characteristics of compounds that cross the blood-brain barrier. BMC Neurol 9(1):S3

Best BM, Koopmans PP, Letendre SL et al (2011) Efavirenz concentrations in CSF exceed IC50 for wild-type HIV. J Antimicrob Chemother 66(2):354-357

Best BM, Letendre SL, Koopmans PP et al (2012) Low cerebrospinal fluid concentrations of the nucleotide HIV reverse transcriptase inhibitor, tenofovir. J Acquir Immune Defic Syndr 59:376-381

Bonora S, Nicastri E, Calcagno A et al (2009) Ultrasensitive assessment of residual HIV viraemia in HAART-treated patients with persistently undetectable plasma HIV-RNA: a cross-sectional evaluation. J Med Virol 81(3):400-405

Bouchat S, Gatot JS, Kabeya K et al (2012) Histone methyltranferase inhibitors induce HIV-1 recovery in resting GD4(+) T cells from HIV-1infected HAART-treated patients. AIDS 26:1473-1482

Bowman NM, Joseph SB, Kincer LP et al. (2016) HIV compartmentalization in the CNS is associated with neurocognitive impairment. Abs 401, Conference on Retroviruses and Opportunistic Infections, February 22-25, 2016, Boston, MA, USA

Busquets MA, Espargaró A, Sabaté R, Estelrich J (2015) Magnetic nanoparticles cross the Blood-brain Barrier: when physics rises to a challenge. Nanomaterials 5:2231-2248

Buzón MJ, Massanella M, Llibre JM et al (2010) HIV-1 replication and immune dynamics are affected by raltegravir intensification of HAARTsuppressed subjects. Nat Med 16:460-466

Canestri A, Ghosn J, Wirden M et al (2006) Foscarnet salvage therapy for patients with late-stage HIV disease and multiple drug resistance. Antivir Ther 11(5):561-566 
Canestri A, Lescure FX, Jaureguiberry S et al (2010) Discordance between cerebral spinal fluid and plasma HIV replication in patients with neurological symptoms who are receiving suppressive antiretroviral therapy. Clin Infect Dis 50:773-778

Chen H, Qin Y, Zhang Q et al (2011) Lactoferrin modified doxorubicinloaded procationic liposomes for the treatment of gliomas. Eur J Pharm Sci 44:164-173

Chen YC, Wen S, Shang SA, Cui Y, Luo B, Teng GJ (2014) Magnetic resonance and near-infrared imaging using a novel dual-modality nano-probe for dendritic cell tracking in vivo. Cytotherapy 16:699-710

Cheng Y, Dai Q, Morshed RA et al (2014) Blood-brain barrier permeable gold nanoparticles: an efficient delivery platform for enhanced malignant glioma therapy and imaging. Small 29(10):5137-5150

Cherukula K, Lekshmi KM, Uthaman S et al (2016) Multifunctional inorganic nanoparticles: recent progress in thermal therapy and imaging. Nanomaterials 6:76

Chi X, Huang D, Zhao Z et al (2012) Nanoprobes for in vitro diagnostics of cancer and infectious diseases. Biomaterials 33:189-206

Choi SJ, Lee JK, Jeong J et al (2013) Toxicity evaluation of inorganic nanoparticles: considerations and challenges. Mol Cell Toxicol 9:205-210

Churchill MJ, Wesseling ML, Cowley D et al (2009) Extensive astrocyte infection is prominent in human immunodeficiency virus-associated dementia. Ann Neurol 66:253-258

Cooper DR, Bekah D, Nadeau JL (2014) Gold nanoparticles and their alternatives for radiation therapy enhancement. Front Chem 2:86

Corot C, Warlin D (2013) Superparamagnetic iron oxide nanoparticles for MRI: contrast media pharmaceutical company R\&D perspective. WIREs Nanomed Nanobiotechnol 5:411-422

Corsi F, Fiandra L, De Palma C et al (2011) HER2 Expression in breast cancer cells is downregulated upon active targeting by antibody-engineered 
multifunctional nanoparticles in mice. ACS Nano 5:6383-6393

Corsi F, Sorrentino L, Mazzucchelli M et al (2016) Antiretroviral therapy through barriers: a prominent role for nanotechnology in HIV-1 eradication from sanctuaries. J Pharm Pharmacol 4:328-339

Croteau D, Rossi S, Best B et al (2013) Darunavir is predominantly unbound to protein in cerebrospinal fluid and concentrations exceed the wild-type HIV-1 median 90\% inhibitory concentration. J Antimicrob Chemother 68:684-689

Cusini A, Vernazza P, Yerly S et al (2013) Higher CNS penetrationeffectiveness of long-term combination antiretroviral therapy is associated with better HIV-1 viral suppression in cerebrospinal fluid. J Acquir Immune Defic Syndr 62:28-35

Cysique LA, Brew BJ (2011) Prevalence of non-confounded HIV-associated neurocognitive impairment in the context of plasma HIV RNA suppression. J Neurovirol 17:176-183

Dahl V, Peterson J, Fuchs D, Gisslen M, Palmer S, Price RW (2014) Low levels of HIV-1 RNA detected in the cerebrospinal fluid after up to 10 years of suppressive therapy are associated with local immune activation. AIDS 28:2251-2258

Darcis G, Koula A, Bouchet S et al (2015) An in-depth comparisn of latency-reversing agent combinations in various in vitro and ex vivo HIV-1 latency models identified bryostatin-1 + JQ1 and and ingenol-B + JQ1 to potently reactivate viral gene expression. PLoS Pathog 11, e1005063

Dash PK, Gendelman HE, Roy U et al (2012) Long-acting nanoformulated antiretroviral therapy elicits potent antiretroviral and neuroprotective responses in HIV-1-infected humanized mice. AIDS 26:2135-2144

De Oliveira MF, Chaillon A, Letendre SR, et al. (2016) Compartmentalized HIV DNA Populations Persist in CSF Despite Suppressive ART. Abs 143, Conference on Retroviruses and Opportunistic Infections, February 22-25, 2016, Boston, MA, USA

Delory T, Papot E, Rioux C et al (2015) Foscarnet, zidovudine and 
dolutegravir combination efficacy and tolerability for late stage HIV salvage therapy: a case-series experience. J Med Virol. doi: 10.1002/jmv. 24442

Denayer T, Stöhr T, Van Roy M (2014) Animal models in translational medicine: validation and prediction. New Horiz Trans1 Med 2:5-11

Destache CJ, Belgum T, Goede M et al (2010) Antiretroviral release from poly(dl-lactide-co-glycolide) nanoparticles in mice. J Antimicrob Chemother 65:2183-2187

Di Yacovo MS, Molto' J, Ferrer E et al (2015) Antiviral activity and CSF concentrations of $600 / 100 \mathrm{mg}$ of darunavir/ritonavir once daily in HIV-1 patients with plasma viral suppression. J Antimicrob Chemother 70:1513-1516

Ding H, Sagar V, Agudelo M et al (2014) Enhanced blood-brain barrier transmigration using a novel transferring embedded fluorescent magnetoliposome nanoformulation. Nanotechnology 25:055101

Dou H, Morehead J, Destache CJ et al (2007) Laboratory investigations for the morphologic, pharmacokinetic, and anti-retroviral properties of indinavir nanoparticles in human monocytederived macrophages. Virology 358:148-158

Dou H, Grotepas CB, McMillan JM et al (2009) Macrophage delivery of nanoformulated antiretroviral drug to the brain in a murine model of neuroAIDS. J Immunol 183:661-669

Dusserre N, Lessard C, Paquette N et al (1995) Encapsulation of foscarnet in liposomes modifies drug intracellular accumulation, in vitro anti-HIV-1 activity, tissue distribution and pharmacokinetics. AIDS 9:833-841

Eck W, Nicholson AI, Zentgraf H, Semmler W, Bartling S (2010) Anti-CD4-targeted gold nanoparticles induce specific contrast enhancement of peripheral lymph nodes in X-ray computed tomography of live mice. Nano Lett 10:2318-2322

Edén A, Price RW, Spudich S, Fuchs D, Hagberg L, Gisslén M (2007) Immune activation of the central nervous system is still present after $>4$ 
years of effective highly active antiretroviral therapy. J Infect Dis 196:1779-1783

Edén A, Fuchs D, Hagberg L et al (2010) HIV-1 viral escape in cerebrospinal fluid of subjects on suppressive antiretroviral treatment. J Infect Dis 202:1819-1825

Ehlerding EB, Chen F, Cai W (2016) Biodegradable and renal clearable inorganic nanoparticles. Adv Sci 3:1500223

Ene L, Duiculescu D, Ruta SM (2011) How much do antiretroviral drugs penetrate into the central nervous system? J Med Life 4:432-439

Evering T, Bernard LS, Abolade J, Mohri H, Markowitz M (2016) Relative frequency of drug Resistance mutations on individual HIV-1 genomes in HAND. Abs 406, Conference on Retroviruses and Opportunistic Infections, February 22-25, 2016, Boston, MA, USA

Fiandra L, Colombo M, Mazzucchelli S et al (2015) Nanoformulation of antiretroviral drugs enhances their penetration across the blood brain barrier in mice. Nanomedicine 11:1387-1397

Gerson T, Makarov E, Senanayake TH, Gorantla S, Poluektova LY, Vinogradov SV (2014) Nano-NRTIs demonstrate low neurotoxicity and high antiviral activity against HIV infection in the brain. Nanomedicine 10:177-185

Gill AJ, Kolson DL (2013) Dimethyl fumarate modulation of immune and antioxidant responses: application to HIV therapy. Crit Rev Immunol $33: 307-359$

Ginhoux F, Greter M, Leboeuf M et al (2010) Fate mapping analysis reveals that adult microglia derive from primitive macrophages. Science 330:841-845

Gobbo OL, Sjaastad K, Radomski MW et al (2015) Magnetic nanoparticles in cancer theranostics. Theranostics 5:1249-1263

Gorry P, Onc C, Thorpe J et al (2003) Astrocyte infection by HIV-1: mechanisms of restricted virus replication, and role in the pathogenesis of 
Grant I, Franklin DR Jr, Deutsch R et al (2014) Asymptomatic HIV-associated neurocognitive impairment increases risk for symptomatic decline. Neurology 82:2055-2062

Gray LR, Turville SG, Hitchen TL et al (2014) HIV-1 entry and transinfection of astrocytes involves CD81 vesicles. Plos One 9, e90620

Grinsztejn B, Hosseinipour MC, Ribaudo HJ et al (2014) Effects of early versus delayed initiation of antiretroviral treatment on clinical outcomes of HIV-1 infection: results from the phase 3 HPTN 052 randomised controlled trial. Lancet Infect Dis 14:281-290

Guo J, Gao X, Su L et al (2011) Aptamer-functionalised PEG-PLGA nanoparticles for enhanced anti-glioma drug delivery. Biomaterials 32:8010-8020

Hakre S, Chavez L, Shirakawa K, Verdin E (2011) Epigenetic regulation of HIV latency. Curr Opin HIV AIDS 6:19-24

Han L, Ren Y, Long L et al (2012) Inhibition of C6 glioma in vivo by combination chemotherapy of implantation of polymer wafer and intracarotid perfusion of transferrin-decorated nanoparticles. Oncol Rep 27:121-128

Harezlak J, Buchthal S, Taylor M, Navia B (2011) Persistence of HIV-associated cognitive impairment, inflammation, and neuronal injury in era of highly active antiretroviral treatment. AIDS 25:625-633

Hellmuth J, Spudich S, Sailasuta N et al. (2016) Acute HIV plasma/CSF HIV RNA ratios are variable and greater than in chronic HIV. Abs 438, Conference on Retroviruses and Opportunistic Infections, February 22-25, 2015, Seattle, WA, USA

Hemmelman M, Knoth C, Schmitt U et al (2011) HPMA based amphiphilic copolymers mediate central nervous effects of domperidone. Macromol Rapid Commun 32:712-717 
Hong S, Banks WA (2015) Role of the immune system in HIV-associated neuroinflammation and neurocognitive implications. Brain Behav Immun $45: 1-12$

https://clinicaltrials.gov/ct2/show/NCT00672932 . Accessed 25 Sept 2017 https://clinicaltrials.gov/ct2/show/NCT01600170 . Accessed 25 Sept 2017 https://clinicaltrials.gov/ct2/show/NCT01978743 . Accessed 25 Sept 2017 https://clinicaltrials.gov/ct2/show/NCT02285374 . Accessed 25 Sept 2017 https://clinicaltrials.gov/ct2/show/NCT02750059 . Accessed 25 Sept 2017 Jafari S, Dizaj SM, Adibkia K (2015) Cell-penetrating peptides and their analogues as novel nanocarriers for drug delivery. BioImpacts 5:103-111

Jayant RD, Atluri VS, Agudelo M, Sagar V, Kaushik A, Nair M (2015) Sustained-release nanoART formulation for the treatment of neuroAIDS. Int J Nanomedicine 10:1077-1093

Jefferies WA, Brandon MR, Hunt SV, Williams AF, Gatter KC, Mason DY (1984) Transferrin receptor on endothelium of brain capillaries. Nature 312:162-163

Jessen Krut J, Mellberg T, Price RW et al (2014) Biomarker evidence of axonal injury in neuroasymptomatic HIV-1 patients. PLoS One 9, e88591

Joseph SB, Arrildt KT, Sturdevant CB, Swanstrom R (2015) HIV-1 target cells in the CNS. J Neurovirol 21:276-289

Joseph SB, Kincer LP, Bowman NM et al. (2016) Persistent HIV-1 in the CNS During Therapy: Evidence of a Viral Reservoir in the CNS. Abs 406, Conference on Retroviruses and Opportunistic Infections, February 22-25, 2016, Boston, MA, USA

Kandel CS, Walmsley SL (2015) Dolutegravir - a review of the pharmacology, efficacy, and safety in the treatment of HIV. Drug Des Devel Ther 9:3547-3555 
Kanmogne G, Singh S, Roy U et al (2012) Mononuclear phagocyte intercellular crosstalk facilitates transmission of cell-targeted nanoformulated antiretroviral drugs to human brain endothelial cells. Int $\mathbf{J}$ Nanomedicine 7:2373-2388

Kaur IP, Bhandari R, Bhandari S et al (2008) Potential of solid lipid nanoparticles in brain targeting. J Control Release 127:97-109

Kim RB, Fromm MF, Wandel C et al (1998) The drug transporter P-glycoprotein limits oral absorption and brain entry of HIV-1 protease inhibitors. J Clin Invest 101:289-294

Kimata JT, Rice AP, Wang J (2016) Challenges and strategies for the eradication of the HIV reservoir. Curr Opin Immunol 42:65-70

Kobayashi T (2011) Cancer hyperthermia using magnetic nanoparticles. Biotechnol J 6:1342-1347

Kramer-Hämmerle S, Rothenaigner I, Wolff H, Bell JE, Brack-Werner R (2005) Cells of the central nervous system as targets and reservoirs of the human immunodeficiency virus. Virus Res 111:194-213

Kreuter J (2014) Drug delivery to the central nervous system by polymeric nanoparticles: what do we know? Adv Drug Deliv Rev 71:2-14

Kuo YC, Chen HH (2006) Effect of nanoparticulate polybutylcyanoacrylate and methylmethacrylatesulfopropylmethacrylate on the permeability of zidovudine and lamivudine across the in vitro blood-brain barrier. Int J Pharm 327:160-169

Kuo YC, Chen HH (2009) Entrapment and release of saquinavir using novel cationic solid lipid nanoparticles. Int J Pharm 365:206-213

Kuo YC, Lee CL (2012) Methylmethacrylate-sulfopropylmethacrylate nanoparticles with surface RMP-7 for targeting delivery of antiretroviral drugs across the blood-brain barrier. Colloids Surf B: Biointerfaces $90: 75-82$

Lai F, Fadda AM, Sinico C (2013) Liposomes for brain delivery. Expert Opin Drug Deliv 10:1003-1022 
Lamers SL, Rose R, Nolan DJ, et al. (2016) HIV DNA Identified in Most Tissues of a Plasma-Negative HIV Autopsy Cohort. Abs 345, Conference on Retroviruses and Opportunistic Infections, February 22-25, 2016, Boston, MA, USA

Letendre S, Best B, Breidinger S et al. (2009) Raltegravir concentrations in CSF exceed the median inhibitoryconcentration. 49th ICAAC (Interscience Conference on Antimicrobial Agents and Chemotherapy). September 12-15, 2009. San Francisco. Abstract A-1311

Letendre SL, Mills AM, Tashima KT et al (2014) ING116070: a study of the pharmacokinetics and antiviral activity of dolutegravir in cerebrospinal fluid in HIV-1-infected, antiretroviral therapy-naive subjects. Clin Infect Dis 59:1032-1037

Li G, Anderson C, O'Major E, Nath A (2106) HIV Infection in Astrocytes Via a CD4-Independent, CXCR4-Dependent Mechanism. Abs 393, Conference on Retroviruses and Opportunistic Infections, February 22-25, Boston, MA, USA

Liu D, Lin B, Shao W et al (2014) In vitro and in vivo studies on the transport of PEGylated silica nanoparticles across the blood-brain barrier. ACS Appl Mater Interfaces 6:2131-2136

Lu CT, Zhao YZ, Wonfg HL, Cai J et al (2014) Current approaches to enhance CNS delivery of drugs across the brain barriers. Int $\mathrm{J}$ Nanomedicine 9:2241-2257

Luzuriaga K, Gay H, Ziemniak C et al (2015) Viremic relapse after HIV-1 remission in a perinatally infected child. N Engl J Med 372:786-788

Mahajan SD, Roy I, Xu G et al (2010) Enhancing the delivery of antiretroviral drug "Saquinavir" across the blood brain barrier using nanoparticles. Curr HIV Res 8:396-404

Manjunath K, Venkateshwarlu V (2006) Pharmacokinetics, tissue distribution and bioavailability of nitrendipine solid lipid nanoparticles after intravenous and intraduodenal administration. J Drug Target $14: 632-645$ 
Massanella M, Ouchi D, Marfil S et al (2014) Different plasma markers of inflammation are influenced by immune recovery and cART composition or intensification in treated HIV infected individuals. PLoS One 9, e114142

McArthur JC, Haughey N, Gartner S et al (2003) Human immunodeficiency virus-associated dementia: an evolving disease. J Neurovirol 9:205-221

Miller LK, Kobayashi Y, Chen CC, Russnak TA, Ron Y, Dougherty JP (2013) Proteasome inhibitors act as bifunctional antagonists of human immunodeficiency virus type 1 latency and replication. Retrovirology 10:120

Mills AM, Antinori A, Clotet B et al (2013) Neurological and psychiatric tolerability of rilpivirine (TMC278) vs. efavirenz in treatment-naïve, HIV-1-infected patients at 48 weeks. HIV Med 14:391-400

Mishra V, Mahor S, Rawat A et al (2006) Targeted brain delivery of AZT via transferrin anchored pegylated albumin nanoparticles. J Drug Target 14:45-53

Mitragotri S, Stayton P (2014) Organic nanoparticles for drug delivery and imaging. MRS Bull 39:219-223

Molina JM, Clotet B, van Lunzen J et al (2015) Once-daily dolutegravir versus darunavir plus ritonavir for treatment-naive adults with HIV-1 infection (FLAMINGO): 96 week results from a randomised, open-label, phase 3 b study. Lancet HIV 2(4):e127-e136

Nowacek A, Gendelman HE (2009) NanoART, neuroAIDS and CNS drug delivery. Nanomedicine (London) 4:557-574

Paciotti GF, Meyer L, Weinreich D et al (2004) Colloidal gold: a novel nanoparticle vector for tumor directed drug delivery. Drug Deliv 11:169-183

Perez Valero I, Letendre S, Ellis R et al (2012) Prevalence and risk factors for HIV CSF viral escape: results from the CHARTER and HNRP cohorts. J Int AIDS Soc 15:18189 
Perry VH, Teeling J (2013) Microglia and macrophages of the central nervous system: the contribution of microglia priming and systemic inflammation to chronic neurodegeneration. Semin Immunopathol $35: 601-612$

Petito C, Chen H, Mastri A, Torres-Munoz J, Roberts B, Wood C (1996) HIV infecion of choroid plexus in AIDS and asymptomatic HIV-infected patients suggests that the choroids plexus may be a reservoir of productive infection. J Neurovirol 5:670-677

Petri B, Bootz A, Khalansky A et al (2007) Chemotherapy of brain tumour using doxorubicin bound to surfactant-coated poly(butyl cyanoacrylate) nanoparticles: revisiting the role of surfactants. J Control Release $117: 51-58$

Pinnetti C, Lorenzini P, Forbici F, et al. (2014) CSF viral escape in patients without neurological disorders: prevalence and associated factors. Abs 443 Conference on Retroviruses and Opportunistic Infections, March 3-6, Boston, MA, USA

Policicchio BB, Pandrea I, Apetrei (2016) Animal models for HIV cure research. Front Immunol 7:12

Price RW, Parham R, Kroll JL et al (2008) Enfuvirtide cerebrospinal fluid (CSF) pharmacokinetics and potential use in defining CSF HIV-1 origin. Antivir Ther 13(3):369-374

Qiao R, Jia Q, Hüwel S et al (2012) Receptor-mediated delivery of magnetic nanoparticles across the blood-brain barrier. ACS Nano $6: 3304-3310$

Qin Y, Zhang Q, Chen H et al (2012) Comparison of four different peptides to enhance accumulation of liposomes into the brain. J Drug Target $20: 235-245$

Rao KS, Reddy MK, Horning JL, Labhasetwar V (2008) TAT-conjugated nanoparticles for the CNS delivery of anti-HIV drugs. Biomaterials 29:4429-4438

Rasmussen TA, Schmeltz Sogaard O, Brinkmann C et al (2013) 
Comparison of HDAC inhibitors in clinical development: effect on HIV production in latently infected cells and T-cell activation. Hum Vaccin Immunother 9:993-1001

Rawson T, Muir D, Mackie NE, Winston A (2012) Factors associated with cerebrospinal fluid HIV RNA in HIV infected subjects undergoing lumbar puncture examination in a clinical setting. J Infect 65:239-245

Re F, Cambianica I, Zona C et al (2011) Functionalization of liposomes with ApoE-derived peptides at different density affects cellular uptake and drug transport across a blood-brain barrier model. Nanomedicine $7: 551-559$

Robillard KR, Chan GN, Zhang G, la Porte C, Cameron W, Bendayan R (2014) Role of P-glycoprotein in the distribution of the HIV protease inhibitor atazanavir in the brain and male genital tract. Antimicrob Agents Chemother 58:1713-1722

Sáez-Cirión A, Bacchus C, Hocqueloux L et al (2013) Post-treatment HIV-1 controllers with a long-term virological remission after the interruption of early initiated antiretroviral therapy ANRS VISCONTI Study. PLoS Pathog 9, e1003211

Sagar VV, Pilakka-Kanthikeel S, Pottathil R, Saxena SK, Nair M (2014) Towards nanomedicines for neuroAIDS. Rev Med Virol 24:103-124

Saiyed ZM, Gandhi NH, Nair MP (2010) Magnetic nanoformulation of azidothymidine 5'-triphosphate for targeted delivery across the blood-brain barrier. Int J Nanomedicine 5:157-166

Sarmati L, Parisi SG, Montano M et al (2012) Nevirapine use, prolonged antiretroviral therapy and high CD4 nadir values are strongly correlated with undetectable HIV-DNA and -RNA levels and CD4 cell gain. J Antimicrob Chemother 67:2932-2938

Saucier-Sawyer JK, Deng Y, Seo Y-E et al (2015) Systemic Delivery of blood-brain barrier targeted polymeric nanoparticles enhances delivery to brain tissue. J Drug Target 23:736-749

Schinkel AH (1999) P-Glycoprotein, a gatekeeper in the blood-brain 
barrier. Adv Drug Deliv Rev 36:179-194

Schnell G, Joseph S, Spudich S, Swanstrom R (2011) HIV-1 replication in the central nervous system occurs in two distinct cell types. PLoS Pathog 7, e1002286

Senanayake TH, Gorantla S, Makarov E, Lu Y, Warren G, Vinogradov SV (2015) Nanogel-conjugated reverse transcriptase inhibitors and their combinations as novel antiviral agents with increased efficacy against HIV-1 Infection. Mol Pharm 12:4226-4236

Shan L, Yang HC, Rabi SA et al (2011) Influence of host gene trasncription level and orientation on HIV-1 latency in a primary cell model. J Virol 85:5384-53693

Shultz LD, Ishikawa F, Greiner DL (2007) Humanized mice in translational biomedical research. Nat Rev Immunol 7:118-130

Singh M, Singh P, Vaira D, Amand M, Rahmouni S, Moutschen M (2014) Minocycline attenuates HIV-1 infection and suppresses chronic immune activation in humanized NOD/LtsZ-scidIL- $2 \mathrm{R} \gamma^{\text {null }}$ mice. Immunology $142: 562-572$

Singh I, Swami R, Pooja D et al (2016) Lactoferrin bioconjugated solid lipid nanoparticles: a new drug delivery system for potential brain targeting. J Drug Target 24:212-223

Solas C, Lafeuillade A, Halfon P, Chadapaud S, Hittinger G, Lacarelle B (2003) Discrepancies between protease inhibitor concentrations and viral load in reservoirs and sanctuary sites in human immunodeficiency virusinfected patients. Antimicrob Agents Chemother 47:238-243

Spivak AM, Bosque A, Balch AH, Smyth D, Martins L, Planelles V (2015) Ex vivo bioactivity and latency reversal by ingenol dibenzoate and panobinostat in resting CD4+ T cells from aviremic patients. Antimicrob Agents Chemother 59:5984-5991

Stefic K, Chaillon A, Bouvin-Pley M et al. (2016) CNS compartmentalization of HIV-1 and sensitivity to neutralizing antibodies. Abs 400, Conference on Retroviruses and Opportunistic Infections, 
Steiniger SC, Kreuter J, Khalansky AS et al (2004) Chemotherapy of glioblastoma in rats using doxorubicin-loaded nanoparticles. Int J Cancer 109:759-767

Sturdevant CB, Joseph SB, Schnell G et al (2015) Compartmentalized replication of R5 T cell-tropic HIV-1 in the central nervous system early in the course of infection. PLoS Pathog 7, e1002286

Sun D, Xue A, Zhang B, Lou H, Shi H, Zhang X (2015) Polysorbate 80-coated PLGA nanoparticles improve the permeability of acetylpuerarin and enhance its brain-protective effects in rats. J Pharm Pharmacol 67:1650-1662

Svicher V, Ceccherini-Silberstein F, Antinori A, Aquaro S, Perno CF (2014) Understanding HIV compartments and reservoirs. Curr HIV/AIDS Rep 11:186-194

Temesgen Z, Siraj DS (2008) Raltegravir: first in class HIV integrase inhibitor. Ther Clin Risk Manag 4:493-500

Thomsen LB, Thomsen MS, Moos T (2015) Targeted drug delivery to the brain using magnetic nanoparticles. Ther Deliv 6:1145-1155

Torchilin VP (2005) Recent advances with liposomes as pharmaceutical carriers. Nat Rev Drug Discov 4:145-160

Tosi G, Costantino L, Rivasi F et al (2007) Targeting the central nervous system: In vivo experiments with peptidederivatized nanoparticles loaded with loperamide and rhodamine-123. J Control Release 122:1-9

Tozzi V, Balestra P, Serraino D et al (2005) Neurocognitive impairment and survival in a cohort of HIV-infected patients treated with HAART. AIDS Res Hum Retrovir 21:706-713

Tozzi V, Balestra P, Bellagamba R et al (2007) Persistence of neuropsychologic deficits despite long-term highly active antiretroviral therapy in patients with HIV-related neurocognitive impairment. J Acquir Immune Defic Syndr 45:174-182 
Valcour V, Chalemchai T, Sailasuta N et al (2012) Central nervous system viral invasion and inflammation during acute HIV Infection. J Infect Dis $206: 275-282$

Vilella A, Ruozi B, Belletti D et al (2015) Endocytosis of nanomedicines: the case of glycopeptide engineered PLGA nanoparticles. Pharmaceutics $7: 74-89$

Wang JX, Sun X, Zhang ZR (2002) Enhanced brain targeting by synthesis of 3',5'-dioctanoyl-5-fluoro-2'-deoxyuridine and incorporation into solid lipid nanoparticles. Eur J Pharm Biopharm 54:285-290

Wang Y, Zhao Q, Han N et al (2015) Mesoporous silica nanoparticles in drug delivery and biomedical applications. Nanomedicine 11:313-327

Watkins CC, Treisman GJ (2015) Cognitive impairment in patients with AIDS - prevalence and severity. HIV AIDS (Auck1) 7:35-47

Whitney JB, Lim SY, Osuna CE at al (2015) Treatment with a TLR7 agonist induces transient viremia in SIV-infected ART-suppressed monkeys. Abs 108 Conference on Retroviruses and Opportunistic Infections, Seattle, WA, USA

Wilson B, Samanta MK, Santhi K, Kumar KP, Paramakrishnan N, Suresh B (2008) Poly(n-butylcyanoacrylate) nanoparticles coated with polysorbate 80 for the targeted delivery of rivastigmine into the brain to treat Alzheimer's disease. Brain Res 1200:159-168

Wu Y, Briley K, Tao X (2016) Nanoparticle-based imaging of inflammatory bowel disease. Wiley Interdiscip Rev Nanomed Nanobiotechnol 8:300-315

Xu G, Yong KT, Roy I et al (2008) Bioconjugated quantum rods as targeted probes for efficient transmigration across an in vitro blood-brain barrier. Bioconjug Chem 19:1179-1185

Xu G, Mahajan S, Roy I et al (2013) Theranostic quantum dots for crossing blood-brain barrier in vitro and providing therapy of HIV-associated encephalopathy. Front Pharmacol 4:140 
Yilmaz A, Price R, Spudich S, Fuchs D, Hagberg L, Gisslen M (2008)

Persistent intrathecal immune activation in HIV-1-infected individuals on antiretroviral therapy. J Acquir Immune Defic Syndr 47:168-173

Yilmaz A, Watson V, Else L, Gisslèn M (2009) Cerebrospinal fluid maraviroc concentrations in HIV-1 infected patients. AIDS 23(18):2537-2540

Yilmaz A, Watson V, Dickinson L, Back D (2012) Efavirenz pharmacokinetics in cerebrospinal fluid and plasma over a 24-hour dosing interval. Antimicrob Agents Chemother 56(9):4583-4585

Ying X, Wen He, Lu WL et al (2010) Dual-targeting daunorubicin liposomes improve the therapeutic efficacy of brain glioma in animals. $\mathrm{J}$ Control Release 141:183-192

Zara GP, Cavalli R, Bargoni A, Fundaro A, Vighetto D, Gasco MR (2002) Intravenous administration to rabbits of non-stealth and stealth doxorubicin loaded solid lipid nanoparticles at increasing concentrations of stealth agent: pharmacokinetics and distribution of doxorubicin in brain and other tissues. J Drug Target 10:327-335

Zhang YL, Ouyang YB, Liu LG, Chen DX (2015) Blood-brain barrier and neuro-AIDS. Eur Rev Med Pharmacol Sci 19:4927-4939

Zhao M, Liang C, Li A et al (2010) Magnetic paclitaxel nanoparticles inhibit glioma growth and improve the survival of rats bearing glioma xenografts. Anticancer Res 30:2217-2224

Fletcher CV, Staskus K, Wietgrefe SW et al (2014) Persistent HIV-1 replication is associated with lower antiretroviral drug concentrations in lymphatic tissues. PNAS 111(6):2307-2312 